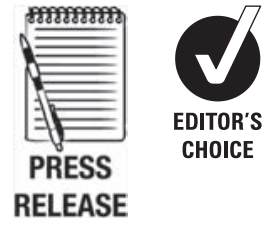

'Department of Health Sciences, Community and Occupational Medicine, University Medical Center Groningen, University of Groningen, The Netherlands ${ }^{2}$ Department of Paediatrics, Division of Neonatology, University Medical Center Groningen, University of Groningen, The Netherlands

\section{Correspondence to}

Marieke R Potijk, Department of Health Sciences,

Community and Occupational Medicine, University Medical Center Groningen, University of Groningen, Antonius Deusinglaan 1, P0 Box 196, 9700 AD Groningen,

The Netherlands; m.r.potijk01@umcg.nl

Received 1 April 2011 Accepted 21 October 2011 Published Online First 6 December 2011

\title{
Higher rates of behavioural and emotional problems at preschool age in children born moderately preterm
}

\author{
Marieke R Potijk, ${ }^{1}$ Andrea F de Winter, ${ }^{1}$ Arend F Bos, ${ }^{2}$ Jorien M Kerstjens, ${ }^{2}$ \\ Sijmen A Reijneveld ${ }^{1}$
}

\begin{abstract}
Objective To compare preschool children born moderately preterm (MP; 32-35 weeks' gestation) and children born at term (38-41 weeks' gestation) regarding the occurrence of behavioural and emotional problems, overall, for separate types of problems and by gender.

Design Prospective cohort study consisting of a community-based sample of MP and a random sample of term-born children in 13 Preventive Child Healthcare centres throughout the Netherlands.
\end{abstract}

Patients $995 \mathrm{MP}$ and 577 term-born children just under age 4 were included.

Main outcome measures Behavioural and emotional problems were measured using the Child Behavior Checklist $1.5-5$ years. Seven syndrome scales, internalising, externalising and total problems were determined. Higher scores indicate worse outcomes. Results MP children had higher scores on all syndrome scales, internalising, externalising and total problems than term-born controls. The mean difference on total problems was $4.04(95 \% \mathrm{Cl} 2.08$ to 6.00). Prevalence rates of elevated externalising problem scores were highest in boys (10.5\%) and internalising problems were highest in girls (9.9\%). MP children were at greater risk for somatic complaints (OR 1.92, 95\% Cl 1.09 to 3.38), internalising (OR 2.40, 95\% $\mathrm{Cl} 1.48$ to 3.87), externalising (OR $1.69,95 \% \mathrm{Cl} 1.07$ to 2.67 ) and total problems (OR $1.84,95 \%$ Cl 1.12 to 3.00$)$.

Conclusions Moderate preterm birth affects all domains of behavioural and emotional problems, particularly for girls. MP children should be targeted for the prevention of mental health problems as they have a great impact on developmental and social competencies at school and in the community.

\section{INTRODUCTION}

Worldwide, the preterm birth rate in 2005 was an estimated 9.6\% (12.9 million births). ${ }^{1}$ The highest rates were in Africa (11.9\%) and North America $(10.6 \%)$, and the lowest rates were in Europe $(6.2 \%) .{ }^{1}$ In the Netherlands, $7.7 \%$ of children were born preterm in $2008 .{ }^{2}$ US data show a rise in the preterm birth rate from $9.4 \%$ in 1981 to $12.3 \%$ in 2003, with the highest increase in the rates of moderately preterm-born children (MP; 32-35 weeks' gestation). ${ }^{3}$ The rate of children born very preterm ( $<32$ weeks) remained relatively constant during the same period at $1.8-2.0 \%$. In other words, children born after 32 weeks' gestation comprise more than $85 \%$ of all preterm births. ${ }^{3-5}$

Accumulating evidence shows that MP children are at greater risk for developmental and

\section{What is already known on this topic}

- Children born moderately preterm are at increased risk for neonatal mortality and for short- and long-term health problems.

- It has been suggested that children born moderately preterm may also be at risk for several types of behavioural and emotional problems.

- However, large prospective cohort studies are lacking.

\section{What this study adds}

- The occurrence of behavioural and emotional problems was higher in moderate preterm-born children than in term-born controls, overall and for separate types of problems.

- In both groups the prevalence of behavioural and emotional problems was higher among boys, but being moderately preterm affected girls more than boys.

health problems than term-born children (38-41 weeks' gestation). Several follow-up studies have reported that MP children are not only at risk for short-term morbidity and mortality, ${ }^{6-8}$ but also for numerous developmental and school-related problems in the long term. ${ }^{9-11}$

However, evidence concerning long-term behavioural and emotional problems among MP children is limited. ${ }^{12-16}$ One study on 52 late preterm-born children (born at 34-36 weeks) showed no differences in externalising, internalising, aggressive and anxious/depressed problems compared to term-born children. ${ }^{12}$ In contrast, van Baar et al reported that MP children were more likely to have behavioural and emotional problems at ages 7-9, specifically attention and internalising problems. ${ }^{13}$ A recent study by Talge et al confirmed the presence of more attention and internalising problems in 6-year-old children born at 34-36 weeks' gestation. ${ }^{14}$ Furthermore, Gray et al reported that $\sim 20 \%$ of MP children with low birth weight had behavioural problems at 3,5 and 8 years of age, compared to the expected $10 \%$ in normative samples when using the same cut-off. ${ }^{15} 17$

Although it is shown that very preterm and low birthweight children have considerably more behavioural and emotional problems, ${ }^{18}$ large prospective cohort studies on moderately and 
late preterm-born children are lacking. The few small studies showed conflicting results. ${ }^{12-14}$ Therefore, the purpose of this study was to determine the occurrence of behavioural and emotional problems, overall and for separate types of problems, in a large cohort of MP preschool children and to compare the occurrence with term-born controls. In addition, we assessed these problems by gender.

\section{METHODS \\ Study design}

The Longitudinal Preterm Outcome Project (Lollypop) is a large prospective cohort study designed to investigate the growth, development and general health of children born preterm, with a special focus on MP children. ${ }^{19}$ The Lollypop cohort consists of a community-based sample of MP children (all born between 32 and 36 weeks' gestation) and a random sample of term-born children. When the study was designed, MP children were defined as those born at 32-35 weeks' gestation and so children born at $36^{0}-36^{6}$ weeks' gestation were not included. Parents completed a questionnaire on behavioural and emotional problems just before the scheduled Preventive Child Healthcare (PCH) visit at 4 years of age. The study was approved by the local institutional review board.

\section{Population}

The study children were sampled in 13 randomly selected $\mathrm{PCH}$ centres, which together monitored 45446 children ( $25 \%$ of all children of this age monitored by PCH centres). In the Netherlands, $90-95 \%$ of children are seen regularly by $\mathrm{PCH}$ centres for well child care from birth up to age 4 , free of charge. ${ }^{20}$ The $\mathrm{PCH}$ centres follow the monitoring guidelines of the National Centre for PCH (www.ncj.nl). Each PCH centre provided a sample of all preterm children born during a single year, either from January 2002 to January 2003, or from June 2002 to June 2003. Term-born children were sampled from the same $\mathrm{PCH}$ centres and were in the same age range as the preterm children. After the file of each second preterm child had been selected, the file of the next term-born child served as a control. Children were excluded if they had a congenital malformation or syndrome or if their gestational age could not be verified. For this study children born at less than 32 weeks' gestation were also excluded. Gestational age was calculated by using the last date of menstruation, and confirmed by early ultrasound measurements in $>95 \%$ of cases. Parents were willing to participate for 995 (86.9\%) of the MP and 577 (85.6\%) of the term-born children. Behavioural questionnaire response rates were high, with the parents of $93.3 \%$ of MP and $95.1 \%$ of term-born children returning the questionnaires.

\section{Measures and procedure}

Behavioural and emotional problems were measured using the Child Behavior Checklist (CBCL) for ages 1.5-5. ${ }^{21} 22$ The CBCL 1.5-5 has good psychometric properties and is widely used in diverse service settings and in research. ${ }^{22}$ The reliability and validity of the problem scales have been confirmed for the Dutch version of the CBCL. ${ }^{23} 24$ It consists of 99 problem items and one open-ended item for recording other problems not listed on the form. Each item can be rated by the parent as follows: 0 , not true; 1 , somewhat or sometimes true; or 2, very true or often true. We constructed seven syndrome scales by summing the ratings for the items comprising each syndrome. Subsequently, problem scores were subdivided into three categories: normal range ( $<93$ th percentile), subclinical or borderline range (93rd to 97th percentile), and clinical or elevated range ( $>97$ th percentile). In addition, the scores for two broad groups (internalising and externalising problems), and total problems were calculated. For these scores, cut-offs for subclinical and clinical problems were set at the 84 th and 90th percentiles, respectively, following the CBCL manual. ${ }^{21}$ Internalising problems consist of syndrome scales for emotionally reactive behaviour, anxious/depressed behaviour, somatic complaints and withdrawn behaviour. Externalising problems consist of syndrome scales for attention problems and aggressive behaviour.

Data on background characteristics were collected using a general parental questionnaire that was sent to the parents simultaneously with the CBCL. The questionnaire consisted of questions about the medical condition of the mother during pregnancy, delivery, developmental and medical conditions of the child, family composition and socioeconomic status. Furthermore, retrospective data files for all children were available from PCH centres, paediatricians, midwives and obstetricians. Thus, it was possible to check some important variables such as gestational age and birth weight by referring to two or more data files. When inconsistencies were found, these were checked against information in discharge letters.

\section{Analysis}

We compared behavioural and emotional problems as measured by the CBCL for MP and term-born children at preschool age. First, characteristics (ie, small for gestational age, gender, age of the child at completing the CBCL, family composition, number of siblings, maternal age, educational level and ethnicity) between MP and term-born children were compared using $\chi^{2}$ tests. Second, mean scores were computed for all CBCL scales to identify behavioural problems associated with moderate prematurity. In addition, differences in mean CBCL scores by gender between $\mathrm{MP}$ and term-born children were examined using t tests. All t tests were confirmed by non-parametric Mann-Whitney $U$ tests because of the non-Gaussian distribution of the CBCL scores. Third, we computed the risk for clinical CBCL problem scores in MP versus term-born children, using logistic regression analyses. In a multivariate logistic regression model, results were adjusted for differences in characteristics between the samples. For all statistical analyses SPSS for Windows 16.0 was used. A p value of less than 0.05 was considered to be statistically significant. A Bonferroni correction for multiple $t$ tests in our gender subgroup adjusted the cut-off for statistical significance to be 0.005 .

\section{RESULTS}

Differences in the background characteristics of the preterm and term groups were highly statistically significant as regards gender, family composition and number of siblings, and marginally so for maternal age and educational level (table 1).

Table 2 shows that MP children had higher mean scores on internalising (mean difference (MD) 1.33, 95\% CI 0.67 to 1.98), externalising (MD 1.41, 95\% CI 0.59 to 2.23) and total problems (MD 4.04, 95\% CI 2.08 to 6.00) than term-born children. In the syndrome scales, the greatest differences were seen regarding withdrawn behaviour (MD 0.29, 95\% CI 0.13 to 0.44 ) and attention problems (MD $0.59,95 \%$ CI 0.39 to 0.79 ). Non-parametric testing produced similar results.

Differences in mean CBCL scores between groups tended to be greater in boys than in girls, as presented in table 3 . However, the gender-by-group interaction was not statistically 
Table 1 Characteristics of moderately preterm and term-born children

\begin{tabular}{|c|c|c|c|}
\hline \multirow{3}{*}{ Mean gestational age (weeks) } & Preterm $(n=916)$ & Term $(n=543)$ & \multirow[b]{4}{*}{ p Value } \\
\hline & 34.0 (SD 1.0) & 39.6 (SD 1.0) & \\
\hline & 2244 (SD 465) & $\overline{3553 \text { (SD 488) }}$ & \\
\hline Mean birth weight (g) & $\%(\mathbf{n})$ & $\%(\mathbf{n})$ & \\
\hline \multicolumn{4}{|l|}{ Gestational age (weeks) } \\
\hline 32 & $11.5(105)$ & & \\
\hline 33 & $20.1(184)$ & & \\
\hline 34 & $27.8(255)$ & & \\
\hline 35 & $40.6(372)$ & & \\
\hline 38 & & $17.1(93)$ & \\
\hline 39 & & $26.2(142)$ & \\
\hline 40 & & $35.9(195)$ & \\
\hline 41 & & $20.8(113)$ & \\
\hline$S G A^{*}$ & $9.2(84 / 916)$ & $7.7(42 / 543)$ & 0.4 \\
\hline Gender (male) & $57.2(524 / 916)$ & $49.2(267 / 543)$ & 0.003 \\
\hline Age of child (months) ${ }^{\dagger}$ & & & 0.6 \\
\hline$<43$ & $0.9(7 / 768)$ & $0.6(3 / 467)$ & \\
\hline $43-47$ & $89.6(688 / 768)$ & $91.4(427 / 467)$ & \\
\hline$>47$ & $9.5(73 / 768)$ & $7.9(37 / 467)$ & \\
\hline Family composition & & & 0.005 \\
\hline Two-parent family & $92.7(845 / 912)$ & $96.3(517 / 537)$ & \\
\hline One-parent family & 7.3 (67/912) & $3.7(20 / 537)$ & \\
\hline Number of siblings & & & 0.006 \\
\hline 0 & $18.6(170 / 916)$ & $12.5(68 / 543)$ & \\
\hline 1 & $54.5(499 / 916)$ & $55.2(300 / 543)$ & \\
\hline 2 & $20.7(190 / 916)$ & $23.2(126 / 543)$ & \\
\hline$\geq 3$ & $6.2(57 / 916)$ & $9.0(49 / 543)$ & \\
\hline Maternal age (years) & & & 0.05 \\
\hline$<25$ & $8.5(75 / 885)$ & $6.1(32 / 526)$ & \\
\hline $25-34$ & $73.6(651 / 885)$ & $71.5(376 / 526)$ & \\
\hline$>34$ & $18.0(159 / 885)$ & $22.4(118 / 526)$ & \\
\hline Maternal educational level $^{\ddagger}$ & & & 0.08 \\
\hline Low & $30.5(278 / 912)$ & $25.6(138 / 539)$ & \\
\hline Medium & $43.0(392 / 912)$ & $43.6(235 / 539)$ & \\
\hline High & $26.5(242 / 912)$ & $30.8(166 / 539)$ & \\
\hline Maternal ethnicity & & & 0.6 \\
\hline Netherlands & $94.2(856 / 909)$ & $95.1(507 / 533)$ & \\
\hline Europe & $1.8(16 / 909)$ & $1.9(10 / 533)$ & \\
\hline Outside Europe & 4.1 (37/909) & $3.0(16 / 533)$ & \\
\hline
\end{tabular}

*SGA, small for gestational age, that is, birth weight below the 10th percentile of the Dutch Kloosterman growth charts. †Age at completing the Child Behavior Checklist.

łLow, primary school or less and/or low-level technical and vocational training; medium, high school or medium-level technical and vocational training for 12-16 years; high, university or high-level technical and vocational training for $>16$ years.

Table 2 Differences in mean Child Behavior Checklist (CBCL) scores between moderately preterm and term-born children

\begin{tabular}{|c|c|c|c|c|c|c|}
\hline \multirow[b]{2}{*}{ CBCL problems scale } & \multicolumn{2}{|c|}{ Preterm $(n=916)$} & \multicolumn{2}{|c|}{ Term $(n=543)$} & \multirow[b]{2}{*}{ Difference $(95 \% \mathrm{CI})$} & \multirow[b]{2}{*}{ p Value* } \\
\hline & Mean & SD & Mean & SD & & \\
\hline Total problems & 30.40 & 19.41 & 26.36 & 17.80 & $4.04(2.08$ to 6.00$)$ & $<0.001$ \\
\hline Externalising problems & 12.44 & 8.12 & 11.03 & 7.50 & 1.41 (0.59 to 2.23$)$ & $<0.01$ \\
\hline Internalising problems & 7.93 & 6.71 & 6.60 & 5.85 & 1.33 (0.67 to 1.98$)$ & $<0.001$ \\
\hline Emotionally reactive & 2.75 & 2.67 & 2.34 & 2.31 & 0.41 (0.15 to 0.67$)$ & $<0.01$ \\
\hline Anxious/depressed & 1.78 & 2.06 & 1.43 & 1.74 & 0.35 (0.15 to 0.55$)$ & $<0.01$ \\
\hline Somatic complaints & 2.05 & 2.22 & 1.77 & 1.96 & $0.28(0.06$ to 0.50$)$ & $<0.01$ \\
\hline Withdrawn & 1.35 & 1.52 & 1.07 & 1.38 & $0.29(0.13$ to 0.44$)$ & $<0.001$ \\
\hline Sleep problems & 2.03 & 2.34 & 1.62 & 2.11 & $0.41(0.18$ to 0.65$)$ & $<0.01$ \\
\hline Attention problems & 2.40 & 2.02 & 1.81 & 1.84 & 0.59 (0.39 to 0.79$)$ & $<0.001$ \\
\hline Aggressive behaviour & 10.04 & 6.75 & 9.22 & 6.17 & $0.82(0.14$ to 1.50$)$ & $<0.05$ \\
\hline
\end{tabular}

* $p$ Values calculated by t tests; non-parametric testing provided p values of the same significance for all differences, except for somatic complaints $(p=0.051)$ and aggressive behaviour $(p=0.054)$. 
Table 3 Differences in mean Child Behavior Checklist (CBCL) scores between moderately preterm and term-born children by gender

\begin{tabular}{|c|c|c|c|c|c|c|c|c|}
\hline \multirow[b]{2}{*}{ CBCL problems scale } & \multicolumn{4}{|l|}{ Boys } & \multicolumn{4}{|l|}{ Girls } \\
\hline & Preterm $(n=524)$ & Term $(n=267)$ & Difference $(95 \% \mathrm{CI})$ & p Value* & Preterm $(n=392)$ & Term $(n=276)$ & Difference $(95 \% \mathrm{Cl})$ & p Value* \\
\hline Total problems & 30.99 & 28.52 & $2.47(-0.36$ to 5.30$)$ & 0.08 & 29.60 & 24.26 & 5.34 (2.59 to 8.09 ) & $<0.001$ \\
\hline Internalising problems & 7.64 & 6.95 & $0.69(-0.24$ to 1.61$)$ & 0.14 & 8.32 & 6.26 & 2.05 (1.08 to 3.03 ) & $<0.001$ \\
\hline Emotionally reactive & 2.77 & 2.54 & $0.23(-0.15$ to 0.62$)$ & 0.22 & 2.71 & 2.14 & 0.58 (0.21 to 0.94$)$ & $<0.01$ \\
\hline Withdrawn & 1.29 & 1.18 & $0.11(-0.11$ to 0.33$)$ & 0.35 & 1.44 & 0.96 & 0.48 (0.27 to 0.69 ) & $<0.001$ \\
\hline Sleep problems & 2.01 & 1.55 & 0.46 (0.13 to 0.79$)$ & $<0.01$ & 2.07 & 1.69 & 0.38 (0.03 to 0.73 ) & $<0.05$ \\
\hline Attention problems & 2.56 & 2.05 & 0.51 (0.21 to 0.81 ) & $<0.01$ & 2.19 & 1.58 & 0.61 (0.33 to 0.89$)$ & $<0.001$ \\
\hline Aggressive behaviour & 10.53 & 10.52 & $0.02(-0.99$ to 1.02$)$ & 0.98 & 9.38 & 7.96 & $1.42(0.51$ to 2.32$)$ & $<0.01$ \\
\hline
\end{tabular}

${ }^{*} p$ Values calculated by $t$ tests; non-parametric testing provided $p$ values of the same significance for all differences except for aggressive behaviour ( $\left.p=0.016\right)$ and externalising behaviour $(p=0.002)$ in girls, and attention problems $(p=0.001)$ in boys.
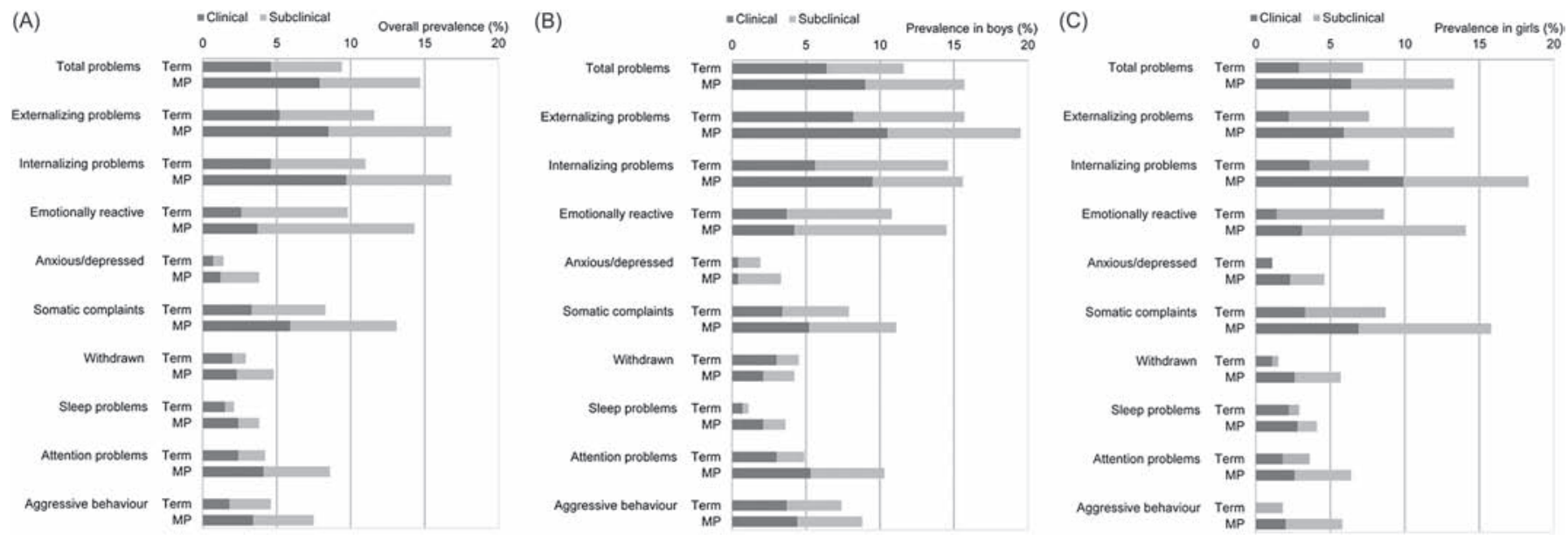

Figure 1 (A) Prevalence rates of behavioural and emotional problems in moderately preterm (MP) and term-born children. For total, externalising and internalising problems, 'clinical' indicates scores $>90$ th percentile and 'subclinical' indicates scores $>84$ th and $<90$ th percentiles. For the syndrome scales, 'clinical' indicates scores $>97$ th percentile and 'subclinical' indicates scores $>93$ th and $<97$ th percentiles. (A) 0verall prevalence. (B) Prevalence in boys. (C) Prevalence in girls.

significant. Among boys, mean scores on two syndrome scales, sleep problems and attention problems, were significantly higher in MP than in term-born children. Among MP girls, mean scores on all seven syndrome scales, as well as on internalising, externalising and total problems, were significantly higher than among term-born girls (table 3 ).

The prevalence rates of subclinical and clinical CBCL problem scores are presented in figure $1 \mathrm{~A}-\mathrm{C}$. Among all MP children, $6.8 \%$ had a total problems score in the subclinical range and $7.9 \%$ had a score in the clinical range (combined $14.7 \%$ ). For term-born children, these figures were $4.8 \%$, and $4.6 \%$, respectively (combined $9.4 \%$ ) (figure $1 \mathrm{~A}$ ). Total problem scores in the clinical range were more prevalent in MP boys than in MP girls (9.0\% vs $6.4 \%$ ) (figure $1 \mathrm{~B}, \mathrm{C})$. The risk for a clinical total problems score compared with term-born peers was lower for MP boys (OR 1.52, 95\% CI 0.84 to 2.75) than for MP girls (OR 2.62, 95\% CI 1.09 to 6.26). MP boys had the highest prevalence rates of elevated externalising problem scores $(9.0 \%$ subclinical and $10.5 \%$ clinical), while MP girls had the highest prevalence rates of elevated internalising problem scores $(8.4 \%$ subclinical and $9.9 \%$ clinical).
Finally, ORs of the risk of clinical CBCL problem scores in $\mathrm{MP}$ children are given in table 4. Compared with term-born children, MP children were at significantly higher risk for clinical CBCL scores for total problems (OR 1.84, 95\% CI 1.12 to 3.00 ), internalising problems (OR 2.40, 95\% CI 1.48 to 3.87 ), externalising problems (OR 1.69, 95\% CI 1.07 to 2.67 ) and somatic complaints (OR 1.92, 95\% CI 1.09 to 3.38).

\section{DISCUSSION}

In this study, we have provided evidence that behavioural and emotional problems occur more frequently in MP than in term-born children at preschool age. The syndrome scales emotionally reactive, anxious/depressed, somatic complaints, withdrawn behaviour, sleep problems, attention problems and aggressive behaviour were all associated with moderate prematurity. Furthermore, we found that MP children were at greater risk for clinical CBCL scores on total problems, internalising and externalising problems, and on somatic complaints.

Our finding that MP children have more behavioural and emotional problems confirms the findings of most previous studies, but in a much larger sample, and at a different age. ${ }^{12-16}$ 
Table 4 Risk for clinical problem scores on the Child Behavior Checklist (CBCL) in moderately preterm versus term-born children

\begin{tabular}{|c|c|c|c|c|}
\hline CBCL problems scale & $\begin{array}{l}\text { Preterm, n (\%) } \\
(n=916)\end{array}$ & $\begin{array}{l}\text { Term, n }(\%) \\
(n=543)\end{array}$ & $\mathrm{uOR}^{*}$ & aOR $(95 \% \mathrm{CI}) \dagger$ \\
\hline Total problems & $72(7.9)$ & $25(4.6)$ & 1.77 & $1.84(1.12 \text { to } 3.00)^{\ddagger}$ \\
\hline Externalising problems & $87(8.5)$ & $28(5.2)$ & 1.71 & $1.69(1.07 \text { to } 2.67)^{\ddagger}$ \\
\hline Internalising problems & $89(9.7)$ & $25(4.6)$ & 2.23 & $2.40(1.48 \text { to } 3.87)^{\ddagger}$ \\
\hline Emotionally reactive & $34(3.7)$ & $14(2.6)$ & 1.46 & $1.70(0.86$ to 3.34$)$ \\
\hline Anxious/depressed & $11(1.2)$ & $4(0.7)$ & 1.64 & $2.50(0.68$ to 9.19$)$ \\
\hline Somatic complaints & $54(5.9)$ & $18(3.3)$ & 1.83 & $1.92(1.09$ to 3.38$) \ddagger$ \\
\hline Withdrawn & $21(2.3)$ & $11(2.0)$ & 1.14 & 1.38 (0.62 to 3.09 ) \\
\hline Sleep problems & $22(2.4)$ & $8(1.5)$ & 1.65 & 1.88 (0.79 to 4.49$)$ \\
\hline Attention problems & $38(4.1)$ & $13(2.3)$ & 1.76 & 1.80 (0.90 to 3.59$)$ \\
\hline Aggressive behaviour & $31(3.4)$ & $10(1.8)$ & 1.87 & $2.03(0.95$ to 4.36$)$ \\
\hline
\end{tabular}

In this study, MP children had significantly worse scores than term-born children on all subscales, internalising, externalising and total problems. Two previous studies also reported more internalising behaviour problems in MP children, ${ }^{13} 14$ and three studies reported more problems in the hyperactivity spectrum such as attention problems. ${ }^{13} 1416$ In addition, we found significantly more externalising behaviour problems in $\mathrm{MP}$ children, in contrast to the findings of van Baar et al in 7-9-year-old Dutch children, and we also found more withdrawn behaviour problems. ${ }^{13}$ These differences may have gone unnoticed in those earlier studies because much smaller samples were investigated. However, the reported differences seem to have clinical relevance, as ORs for MP children compared to term-born children were in a range similar to that previously reported for very preterm and very low birthweight (VP/VLBW) children. ${ }^{26}$ Only one study reported no differences between children born at 34-36 weeks and children born at term for externalising, internalising, aggressive and anxious/depressed problems. ${ }^{12}$ This may be because that study was restricted to relatively healthy children from highincome families. The deleterious effects of preterm birth may be stronger among children born to poor families. ${ }^{25}$

Differences in behavioural and emotional problems by gender have previously been reported in studies on VP/VLBW children. Overall, VP/VLBW girls seem to have more internalising problems, such as withdrawn behaviour, while VP/VLBW boys seem to be more susceptible to externalising behaviour problems, especially attention problems. ${ }^{26-29}$ We found the same pattern of internalising and externalising problems in MP girls and boys but not in term-born children. Among term-born children, both internalising and externalising problems were more prevalent in boys than in girls. On most syndrome scales, prevalence rates were also higher in term-born boys, except for anxious/depressed and sleep problems. To summarise, moderate preterm birth seems to have a greater effect on behavioural and emotional outcomes in girls than in boys. However, the prevalence rates of total problems among MP girls did not particularly differ compared to rates among term-born boys; additional research is required to investigate why prematurity affects behavioural and emotional outcomes more in girls than in boys. Currently, we have no proper explanation and differences in background characteristics do not explain these findings.

Important strengths of this study were its large community based sample, the same method of data collection among MP and term-born children, and its high response rate. Moreover, this is the first study investigating the full range of behavioural and emotional problems in MP children just before they enter school. A valid and widely used questionnaire, the CBCL, ${ }^{21}$ was used to measure behavioural and emotional problems. A large number of parents returned the CBCL questionnaires.

One potential limitation of this study is the fact that we did not obtain professional assessment of behavioural and emotional problems. If the observations of professionals could have been compared with parents' reports, the results of this study would have provided a more complete picture of the behavioural and emotional problems in MP children. However, parent-reported problems can accurately identify psychosocial problems. ${ }^{30}$ Another limitation of this study is the lack of information on some early risk factors for behavioural and emotional problems, such as maternal depression and preschool educational experience. Further research is needed to determine the joint effects of maternal psychological, obstetric and environmental factors on behavioural and emotional problems.

\section{CONCLUSION}

Our results demonstrate that $\mathrm{MP}$ children are more likely to already have behavioural and emotional problems before they enter school. Therefore, MP children could be a potential target group for the prevention of mental health problems, as behavioural and emotional problems in early childhood tend to persist in later childhood and adolescence. ${ }^{31-33}$ Moreover, mental health problems have a great impact on the developmental and social competencies at school and in the community. ${ }^{31-33}$ Interventions at early school age might, for example, include extra support at school or even specialised school services, along with psychological assistance. Our findings need to be confirmed by other studies, as we were the first to assess the full range of behavioural and emotional problems in MP children just before they enter school.

Acknowledgements The authors thank $\mathrm{E} M \mathrm{~J}$ ten Vergert MD, B M van der Hulst MD and M J Broer van Dijk MD, Preventive Child Healthcare doctors, for coordinating the field work.

\section{Competing interest None.}

Funding This study is part of a larger cohort study on the development, growth and health of children born preterm (controlled-trials.com ISRCTN 80622320) and is supported by the research foundation of Beatrix Children's Hospital, the Cornelia Foundation for the Handicapped Child, the A. Bulk-Child Health Care Research Fund, the Dutch Brain Foundation, and unrestricted research grants from Friesland 
Campina, Hero, Abbott and Pfizer Europe. Marieke Potijk was supported by a grant from the Junior Scientific Masterclass of the University of Groningen. The financers had no role at any stage of the project including the decision to submit the manuscript

Provenance and peer review Not commissioned; externally peer reviewed.

\section{REFERENCES}

1. Beck S, Wojdyla D, Say L, et al. The worldwide incidence of preterm birth: a systematic review of maternal mortality and morbidity. Bull World Health Organ 2010;88:31-8

2. Stichting Perinatale Registratie Nederland. Perinatale Zorg in Nederland 2008. [Perinatal Care in The Netherlands 2008]. Utrecht: Stichting Perinatale Registratie Nederland 2011.

3. Davidoff MJ, Dias T, Damus K, et al. Changes in the gestational age distribution among U.S. singleton births: impact on rates of late preterm birth, 1992 to 2002. Semin Perinatol 2006;30:8-15.

4. Martin JA, Hamilton BE, Sutton PD, et al. Births: final data for 2003. Natl Vital Stat Rep 2005:54:1-116.

5. Ananth CV, Joseph KS, Oyelese Y, et al. Trends in preterm birth and perinatal mortality among singletons: United States, 1989 through 2000. Obstet Gynecol 2005; 105:1084-91.

6. Khashu M, Narayanan M, Bhargava S, et al. Perinatal outcomes associated with preterm birth at 33 to 36 weeks' gestation: a population-based cohort study. Pediatrics 2009:123:109-13.

7. Bastek JA, Sammel MD, Paré E, et al. Adverse neonatal outcomes: examining the risks between preterm, late preterm, and term infants. Am J Obstet Gynecol 2008:199:367.e1-8.

8. Kramer MS, Demissie K, Yang H, et al. The contribution of mild and moderate preterm birth to infant mortality. Fetal and Infant Health Study Group of the Canadian Perinatal Surveillance System. JAMA 2000;284:843-9.

9. Petrini JR, Dias T. McCormick MC, et al. Increased risk of adverse neurologica development for late preterm infants. J Pediatr 2009;154:169-76.

10. Morse SB, Zheng H, Tang Y, et al. Early school-age outcomes of late preterm infants. Pediatrics 2009;123:e622-9.

11. Chyi LJ, Lee HC. Hintz SR, et al. School outcomes of late preterm infants: special needs and challenges for infants born at 32 to 36 weeks gestation. J Pediatr 2008:153:25-31.

12. Gurka MJ, LoCasale-Crouch J, Blackman JA. Long-term cognition, achievement, socioemotional, and behavioral development of healthy late-preterm infants. Arch Pediatr Adolesc Med 2010:164:525-32.

13. van Baar AL, Vermaas J, Knots E, et al. Functioning at school age of moderately preterm children born at 32 to 36 weeks' gestational age. Pediatrics 2009:124:251-7.

14. Talge NM, Holzman C, Wang J, et al. Late-preterm birth and its association with cognitive and socioemotional outcomes at 6 years of age. Pediatrics 2010;126:1124-31.

15. Gray RF, Indurkhya A, McCormick MC. Prevalence, stability, and predictors of clinically significant behavior problems in low birth weight children at 3,5 , and 8 years of age. Pediatrics 2004;114:736-43.
16. Huddy CL, Johnson A, Hope PL. Educational and behavioural problems in babies of 32-35 weeks gestation. Arch Dis Child Fetal Neonatal Ed 2001;85:F23-8.

17. Achenbach TM. Manual for the Child Behavior Checklist/4-18 and 1992 Profile. Burlington, VT: University of Vermont Department of Psychiatry 1991.

18. Johnson S, Marlow N. Preterm birth and childhood psychiatric disorders. Pediatr Res 2011;69:11R-8R.

19. Kerstjens JM, Bos AF, ten Vergert EM, et al. Support for the global feasibility of the Ages and Stages Questionnaire as developmental screener. Early Hum Dev 2009;85:443-7.

20. Brugman $\mathbf{E}$, Reijneveld $S A$, Verhulst $F C$, et al. Identification and management of psychosocial problems by preventive Child Health Care. Arch Pediatr Adolesc Med 2001;155:462-9.

21. Achenbach TM, Rescorla LA. Manual for the ASEBA Preschool Forms and Profiles. Burlington, VT: University of Vermont, Research Center for Children, Youth, and Families 2000.

22. Rescorla LA. Assessment of young children using the Achenbach System of Empirically Based Assessment (ASEBA). Ment Retard Dev Disabil Res Rev 2005;11:226-37.

23. Verhulst FC, van der Ende J, Koot HK. Handleiding voor de Youth Self-Report (YSR). [Manual for the Youth Self-Report (YSR)]. Rotterdam: Sophia Children's Hospital 1997.

24. Crone MR, Bekkema N, Wiefferink CH, et al. Professional identification of psychosocial problems among children from ethnic minority groups: room for improvement. J Pediatr 2010;156:277-84.e1.

25. Hille ET, den Ouden AL, Bauer L, et al. School performance at nine years of age in very premature and very low birth weight infants: perinatal risk factors and predictors at five years of age. Collaborative Project on Preterm and Small for Gestational Age (POPS) Infants in The Netherlands. J Pediatr 1994;125:426-34.

26. Reijneveld SA, de Kleine MJ, van Baar AL, et al. Behavioural and emotional problems in very preterm and very low birthweight infants at age 5 years. Arch Dis Child Fetal Neonatal Ed 2006;91:F423-8.

27. Botting N, Powls A, Cooke RW, et al. Attention deficit hyperactivity disorders and other psychiatric outcomes in very low birthweight children at 12 years. $J$ Child Psychol Psychiatry 1997;38:931-41.

28. Sykes DH, Hoy EA, Bill JM, et al. Behavioural adjustment in school of very low birthweight children. J Child Psychol Psychiatry 1997;38:315-25.

29. Johnson S. Cognitive and behavioural outcomes following very preterm birth. Semin Fetal Neonatal Med 2007:12:363-73.

30. Klein Velderman M, Crone MR, Wiefferink $\mathrm{CH}$, et al. Identification and management of psychosocial problems among toddlers by preventive Child Health Care professionals. Eur J Public Health 2010;20:332-8.

31. Breslau J, Miller E, Breslau N, et al. The impact of early behavior disturbances on academic achievement in high school. Pediatrics 2009;123:1472-6.

32. Hofstra MB , van Der Ende J, Verhulst FC. Adolescents' self-reported problems as predictors of psychopathology in adulthood: 10-year follow-up study. Br J Psychiatry 2001;179:203-9.

33. Fergusson DM, Horwood LJ, Ridder EM. Show me the child at seven: the consequences of conduct problems in childhood for psychosocial functioning in adulthood. J Child Psychol Psychiatry 2005;46:837-49. 